\title{
Surgical fires: still a burning issue in England and Wales
}

\author{
Abstract \\ A significant number of surgical fires occur each year and can have devastating effects on \\ patients. The National Reporting and Learning System (NRLS) database identified 37 reports \\ of surgical fires in England and Wales between January 2012 and December 2018-over \\ $52 \%$ resulting in some degree of harm. Surgical fires remain preventable adverse events that \\ can be avoided by adherence to effective preventative strategies and improved education. \\ This article surveys the existing literature, addressing the fire triad and how to effectively \\ manage and prevent a surgical fire.
}

\section{Key words}

Surgical fires, patient safety, adverse events, operating room, communication, burns, education

\section{Introduction}

The term surgical fire rarely elicits the degree of concern that is warranted in light of their continued incidence in the operating theatre worldwide. Although they remain a rare adverse event they, continue to occur with regularity and perioperative staff may be unaware of the risk factors, as well as how to effectively prevent and manage a surgical fire. There has been a decline in awareness to the risk of surgical fire, which is likely correlated with the decline in the use of highly flammable and explosive anaesthetic gases such as cyclopropane over the last 30 years. 
Surgical fires can be subdivided into two kinds: fires that occur in the operating theatre environment - most often involving electrical equipment - and fires that occur on the patient, the latter of which will be the focus in this article. The first recorded surgical fire occurring on a patient as a result of the use of anaesthetic gases goes back to 1850 when ether caught fire during facial surgery (MacDonald 1994). A search of the anaesthetic and surgical literature - especially from the United States (US) — indicates that there has been a noticeable increase in interest in educating perioperative staff on how to prevent surgical fires. This is vital, as surgical fires can have devastating outcomes for patients, such as fatal or disfiguring injuries leading to an extended hospital stay, and they can be psychologically traumatic for patients and the staff involved (Bruley 2017, Choudhry et al 2017, Watson 2010). The most common sites for surgical fires to occur are in the airway, face, neck and upper chest (Bruley 2017, Daane \& Toth 2005, Hart et al 2011, Smith \& Roy 2011, Yardley \& Donaldson 2010). In the US, a surgical fire is estimated to be responsible for the death of 1-2 patients annually; in some studies, the mortality rate was as high as 5\% of surgical fires (Overbey et al 2015, ECRI Institute 2009).

Surgical fires are preventable adverse events that require three components - an oxidizer, ignition source, and fuel—known as the fire triad (Apfelbaum et al 2013). Recognition, separation, and management of the different components of the fire triad are therefore essential to reduce their incidence (Vogel 2018). Other contributory factors include a lack of education, poor team communication, other human factors, equipment design and the absence of evidence-based practice (Bruley 2004, Lampotang et al 2005, Kezze et al 2018). Moreover, with improvement in all of these areas, surgical fires can theoretically be eliminated. It is therefore imperative that perioperative staff are appropriately informed about 
the causes, contributory risk factors and how to prevent and effectively manage a surgical fire.

\section{Incidence}

It is well established that surgical fires are underreported. In some countries this is a result of legal settlements and the absence of a standard reporting system (Yardley \& Donaldson 2010, Sosis 2006). There may also be some concern about discussing the risk of surgical fires due to how it could be perceived by prospective patients and the general public. Rocos and Donaldson (2012) found from a search of the National Reporting and Learning System (NRLS) database that there had been 13 reported surgical fires in the NHS between 2004 and 2011; this number is unlikely to reflect the true number of surgical fires.

A more recent search of the NRLS database identified 37 reports of surgical fires in England and Wales between January 2012 and December 2018. Of the 37 reported surgical fires, 18 $(48 \%)$ resulted in no harm, $8(22 \%)$ in low harm, $8(22 \%)$ in moderate harm and $3(8 \%)$ in severe harm, and therefore $52 \%$ of surgical fires resulted in some degree of harm. The increase in the number of reports from the 2004-2011 period is unlikely to reflect an increase in the incidence of surgical fires but rather improved and more accurate reporting. As already noted above, the data from the NRLS is unlikely to be a true reflection of the number of surgical fires that actually occurred and so the number is likely to be higher. These figures should be alarming to those caring for patients in the perioperative setting and warrant serious consideration and action.

In the US, estimates of the incidence of surgical fires vary significantly between a high of 
550-650 annually to a more recent estimate of between 200-240 (Bruley 2017). There are also a number of published case studies published from around the world detailing the causes of the surgical fire with recommendations on how to prevent similar adverse events (Barker \& Polson 2001, Batra \& Gupta 2008, Beesley \& Taylor 2006, Gorphe et al 2014, Sibia et al 2016, Tan \& Thong 2015). Each one demonstrating the unique contributory factors that can lead to a surgical fire.

\section{The fire triad}

The etiology of a surgical fire is reducible to the three components of the fire triad and can occur when they are all present. All three components are readily available in the perioperative environment with a different member of the team responsible for the fuel, ignition source and oxidizer. This highlights the valuable role that an awareness of the risk factors and effective communication play in preventing surgical fires (Yardley \& Donaldson 2010). By removing just one component of the fire triad the risk of a surgical fire can be eliminated and are therefore wholly preventable.

Insert Figure 1.

\section{Fuel}

Potential fuel for a surgical fire include swabs, endotracheal tubes, bowel gas, dressings, patients hair, smoke evacuator hoses, bone cement, drains, and patient gowns (Abdulrasheed et al 2013, Hart et al 2011, Jones et al 2019, Sibia et al 2016, Yardley \& Donaldson 2010). Two common fuels frequently implicated in surgical fires are drapes and alcohol-based skin 
preparation solutions (Rocos \& Donaldson 2012, Zahiri et al 2011). Any alcohol-based skin preparation is potentially flammable and the higher the concentration, the higher the risk. However, this risk can be mitigated by observing the manufacturer's recommended drying time, allowing the alcohol content to evaporate and minimise the risk of it being ignited. Failing to adhere to the recommended drying time presents an increased risk of surgical fire and this is compounded by the application of the skin preparation that allow it to pool on the patient's skin and hair, or to be absorbed into the drapes or other material (Batra \& Gupta 2008). Where pooling has occurred it should be dried with a swab (which should itself be disposed of so as not to be introduced later by accident) and any material that has absorbed any solution should be removed and replaced. Using a purpose-built applicator can reduce the risk of pooling by limiting the application of excess solution and by not using a larger than necessary applicator. Nevertheless, recent research using porcine skin has shown that even when the recommended drying time was observed, even in the absence of pooling, there remains an increased risk of surgical fire compared to non-alcoholic-based skin preparation solutions (Jones et al 2017).

Drapes remain one of the most common fuels implicated in surgical fires (Smith \& Roy 2011) and therefore should not be applied before the recommended drying time has been observed. It is also possible that if a patient is draped prior to the application of the skin preparation that the alcohol vapors can collect and become trapped and then be ignited following the introduction of a heat source (Batra \& Gupta 2008). It has been suggested by some that due to the increased risk of surgical fire, alcohol-based skin preparation should be avoided where possible. However, this risk must be balanced against evidence-based practice guidance (National Institute for Health and Care Excellence 2019) surrounding the use of the alcohol-based skin preparation solution of chlorhexidine and its association with the lowest 
incidence of surgical site infections (Darouiche et al 2010). Furthermore, there is some evidence that indicates that alcohol-based skin preparation should be avoided in unshaved dense hair-bearing areas on the head and face (Day et al 2018).

\section{Ignition source}

There is a range of ignition sources that can be found in the operating theatre, including electrosurgical devices, lasers, fiberoptic light sources, sparks from surgical drills and defibrillators (Abdulrasheed et al 2013, Hart et al 2011, Zahiri et al 2011). Fiberoptic light sources are frequently described as emitting cold light, however, once disconnected from the endoscope during surgery they can get hot enough to act as an ignition source when in contact with drapes or other materials (Ball, 2014). Controlled experimental studies have shown that electrosurgical devices produce enough heat to ignite all alcohol-based skin preparation solutions, some requiring temperatures of $800-900^{\circ} \mathrm{C}$ to ignite (Batra \& Gupta 2008). Electrosurgical devices such as diathermy can produce temperatures upwards of $1,000^{\circ} \mathrm{C}$ (Vedbhushan et al 2013). Electrosurgical devices are the most frequently indicated ignition source, accounting for around 70-80\% of surgical fires (Batra \& Gupta 2008, Choudhry et al 2017, Day et al 2018, Kaye et al 2014, Yardley \& Donaldson 2012). Lasers may account for $10 \%$ of surgical fires (Bruley 2017) and are the second most common ignition source (Smith \& Roy 2008). Lasers may present a greater individual risk given the relative rarity with which they are used compared with electrosurgical devices (Yardley \& Donaldson 2010). This risk can be diminished during shared-airway surgery by using a laser resistant endotracheal tube, which are rarely used, even when clinically indicated (Day et al 2018). 


\section{Oxidizer}

An oxidizer is a substance that can intensify combustion and accelerate the burning processin the operating theatre the most common are oxygen and nitrous oxide. At sea level the air is composed of $21 \%$ oxygen, however, in certain circumstances, the operating theatre can become an oxidizer-enriched environment, this occurs when the oxygen level rises above 21\% (Daane \& Toth 2005, Kaye et al 2014). An oxidizer-enriched environment creates a situation where there is an increased risk of combustion; the higher the oxygen concentration, the more rapidly ignition occurs, the hotter the fire burns and the harder it is to extinguish (Culp et al 2013, Goldberg 2006, Kaye et al 2014). An oxidizer-enriched environment is complicit in more than 70\% of surgical fires (Bruley 2017). In a recent systematic review looking at 87 otolaryngologic surgical fires, oxidizing agents consisted of oxygen alone in $78 \%$ of cases, oxygen and nitrous oxide in $21 \%$ and just room air in $1 \%$ (Day et al 2018). The most notable risk was associated with the delivery of supplemental oxygen. In one retrospective survey of surgeons who performed periocular surgery, supplemental oxygen was administered in $88 \%$ of surgical fires (Connor et al 2018). Reducing FiO2 to less than $30 \%$ may help to reduce the risk of an airway fire developing (Roy \& Smith 2015). Furthermore, materials that may be fire-resistant in room air may not remain so in an oxidizer-enriched environment (Kezze et al 2018). Oxidizer-enriched environments, therefore, pose a significant surgical fire risk and every attempt should be made to prevent it from occurring.

\section{Management}


It is vital that perioperative staff possess sufficient knowledge of how to identify and manage a surgical fire should one develop-failure to do so can lead to poorer patient outcomes, and can contribute to increased morbidity and mortality (Haith et al 2012). How to effectively extinguish a fire and reduce the harm caused to the patient will depend on a number of factors, primarily, the site of the fire - airway or non-airway. Guidance produced by the American Society of Anesthesiologists (ASA) (Apfelbaum et al 2013) outline five steps that should constitute the management of a surgical fire: (1) recognizing the early signs of fire, (2) halting the procedure, (3) making appropriate attempts to extinguish the fire, (4) following an evacuation protocol when medically appropriate, and (5) delivering postfire care to the patient.

The first signs of a fire can include: smoke, flashes and/or flames and may include a strange odour, unusual sounds, heat, discolouration of drapes or the breathing circuit (Apfelbaum et al 2013, Blazquez \& Thorn 2010, Jones et al 2019). The first signs of fire will be dependent on the cause and site of the fire. Identifying a fire may not always be obvious, for instance, the blue flame given off by an alcohol-based skin preparation solution will be difficult to spot when surrounded by blue drapes (Jones et al 2019). When a member of the perioperative team has identified any of these signs it should be communicated immediately to the rest of the team; surgery should be paused until a fire has been ruled out or extinguished (Apfelbaum et al 2013, Kaye et al 2014). Once identified, the fire should be extinguished immediately and the most effective approach will depend on the site of the fire (Bruley 2004).

\section{Non-airway fire}


In a small non-airway fire it may be sufficient to pat the fire out with a gloved hand and/or remove any burning material from the patient, including drapes, and simultaneously extinguishing with normal saline or water (Abdulrasheed et al 2013, Apfelbaum et al 2013, Bruley 2004, Yardley \& Donaldson 2010, Haith et al, 2012). Priority should be given to extinguishing the fire over maintaining a sterile field. In a larger fire it may be necessary to stop the flow of airway gases and maintain ventilation with a self-inflating bag and to use a carbon dioxide fire extinguisher, which has the benefit of reducing the severity of a thermal injury (Day et al 2018, Haith et al 2012). A fire blanket should not be used as this could trap the fire on the patient (Haith et al 2012, Zahiri et al 2011). Once the fire has been extinguished the patient should then be assessed for thermal injury and treated accordingly (Apfelbaum et al 2013, Haith et al 2012).

\section{Airway fire}

There is unanimous agreement that at the first sign of an airway fire that the endotracheal or tracheostomy tube should be immediately removed and disconnected from the breathing circuit; any additional flammable or burning material should be removed and normal saline should be poured into the airway to cool it (Akhtar et al 2016, Apfelbaum et al 2013, Zahiri et al 2011). There may however be exceptions for extubating a patient during an airway fire. If the patient was a difficult intubation, and there are concerns about re-intubating them successfully then extubation may not be indicated (Chee \& Benumof 1998). In such circumstances, clinicians must therefore quickly assess the risk and benefits between extubating the patient or attempting to extinguish the fire with the patient still intubated (Akhtar et al 2016, Wolf \& Sidebotham 1999). If extubation is not indicated then the breathing circuit can be detached and the endotracheal tube can be flushed with water or 
normal saline. Following the successful extinguishing of the fire, ventilation should recommence - initially with room air - and the patient's airway should be resecured where indicated. The endotracheal tube should be examined to determine if any fragments could still be in the airway, and a bronchoscopy should be performed to ascertain the extent of the inhalation injury and to identify any endotracheal tube fragments or other debris (Apfelbaum et al 2013, Day et al 2018).

Should the fire persist, despite attempts to extinguish it with a carbon dioxide extinguisher, the fire alarm should be activated, and the patient and perioperative team should be evacuated according to local policy. The doors to the operating theatre should be closed to contain the fire and the medical gas supply should be shut off (Hart et al 2011, Miles et al 2015).

\section{Education}

Prevention of surgical fires begins with educating existing perioperative staff and should be mandatory in the relevant clinical undergraduate education-operating department practice, nursing and medical. Although many clinicians receive some form of fire safety training, it may not be sufficient for preventing and managing the unique features of a surgical fire. Education should emphasise the increased risk created by an oxidizer-enriched environment and therefore what constitutes a high-risk procedure (Bruley 2017, Kezze et al 2018). Staff should be aware that in an oxidizer-enriched environment material that would not usually be considered flammable — including fire resistant material — can quickly ignite and burn (Culp et al 2013). High-risk procedures include: ear, nose and throat surgery, maxillofacial surgery, head or neck surgery, laser surgery, laparoscopic surgery and mediastinal surgery (Blazquez \& Thorn 2010). A recent study by Tola et al (2018) from the United States has shown that 
education can help improve knowledge and awareness of surgical fire safety amongst perioperative staff.

\section{Rehearsal}

An additional means of educating perioperative staff involves rehearsing what to do if a surgical fire occurs. This may involve simulation scenarios, which can encourage awareness and discussion about the prevention and management of a surgical fire (Corvetto et al 2011). More recently virtual reality has been used to help prepare perioperative staff to manage a surgical fire (Dorozhkin et al 2017). Whatever approach is utilized it is imperative that all members of the perioperative team are involved, since different members of the team are responsible for the three components of the fire triad (Apfelbaum et al 2013). Rehearsing acts as an additional means of reducing the impact of human factors that can contribute to a worse outcome, such as: slow reaction, distraction, inattentiveness, improper extinguishing techniques and complacency (ECRI Institute 2009, Watson 2010).

\section{Preparation}

It is advisable that a risk assessment tool should be used to assess the risk of a surgical fire and this is especially warranted for surgery considered high risk. This could be a standalone tool or something that can be easily incorporated into the WHO Surgical Safety Checklist at the time-out stage (Dennison 2011, Parremore 2018). The risk assessment tool should provide an indication of the risk of a surgical fire so that staff can adjust their practices and behaviour accordingly_encouraging better communication and increased vigilance. The risk factors that should be considered in any surgical fire risk tool include: surgical site above the 
xiphoid, an open/supplemental oxygen supply (nasal cannula or oxygen mask), presence of an ignition source (e.g. electrosurgery or laser), and the use of alcohol-based skin preparation solutions (Dennison 2011, Mathias 2006, Parremore 2018). Additionally, a visible surgical fire algorithm acting as a cognitive aid could be displayed in each operating theatre to help reinforce knowledge of how to prevent and manage a fire (Jones et al 2019). The ASA have produced an algorithm that outlines fire prevention and management of airway and nonairway surgical fires, which could be easily displayed in each operating theatre (Apfelbaum et al 2013).

\section{Conclusion}

Surgical fires continue to be a risk and because of its potentially devastating effects to patients, perioperative staff must be better informed about how to prevent and effectively extinguish one. This risk is further highlighted by their continued occurrence in England and Wales, resulting in some degree of harm in the majority of cases. Surgical fires are preventable adverse events that theoretically can be eliminated with improved knowledge and preparation. Moreover, it is important that awareness is ongoing and that perioperative teams work together to mitigate the risks. Although surgical fires are rare, the potential for harm is high and therefore places an obligation on staff to reduce and ultimately eliminate their incidence altogether.

\section{References}

Abdulrasheed I, Lawal AM, Eneye AM 2013 Surgical fires: An ongoing intra-operative challenge Archives of International Surgery 3 (1) 1-5 
Akhtar N, Ansar F, Baig MS, Abbas A 2016 Airway fires during surgery: Management and prevention Journal of Anaesthesiology Clinical Pharmacology 32 (1) 109-111

Apfelbaum JL, Caplan RA, Barker SJ et al 2013 Practice advisory for the prevention and management of operating room fires: An updated report by the American Society of Anesthesiologists Task Force on Operating Room Fires Anesthesiology 118 271-90

Ball KA 2014 Surgical Modalities. In: Rothrock JC (ed) Alexander's care of the Patient in Surgery 15th ed St Louis, Elsevier

Barker S, Polson JS 2001 Fire in the operating room: a case report and laboratory study Anesthesia \& Analgesia 93 (4) 960-965

Batra S, Gupta R 2008 Alcohol based surgical prep solution and the risk of fire in the operating room: a case report Patient Safety in Surgery 2 10. https://doi.org/10.1186/1754$\underline{9493-2-10}$

Beesley J, Taylor L 2006 Reducing the risk of surgical fires: are you assessing the risk? Journal of Perioperative Practice 16 (12) 591-597

Blazquez E, Thorn C 2010 Fires and explosions Anaesthesia \& Intensive Care Medicine 11 (11) $455-457$

Bruley ME 2004 Surgical fires: perioperative communication is essential to prevent this rare 
but devastating complication BMJ Quality \& Safety 13 (6) 467-471

Bruley ME 2017 Challenges in Preventing Electrical, Thermal, and Radiation Injuries. In: Sanchez JA, Barach P, Johnson JK, Jacobs JP (ed) Surgical Patient Care: Improving Safety, Quality and Value Cham, Springer

Chee WK, Benumof JL 1998 Airway fire during tracheostomy: extubation may be contraindicated Anesthesiology 89 (6) 1576-1578

Choudhry AJ, Haddad NN, Khasawneh MA, Cullinane DC, Zielinski MD 2017 Surgical fires and operative burns: lessons learned from a 33-year review of medical litigation The American Journal of Surgery 213 (3) 558-564

Connor MA, Menke AM, Vrcek I, Shore JW 2018 Operating room fires in periocular surgery International Ophthalmology 38 (3) 1085-1093

Corvetto MA, Hobbs GW, Taekman JM 2011 Fire in the Operating Room Simulation in Healthcare 6 (6) 356-359

Culp WC Jr, Kimbrough BA, Luna S 2013 Flammability of surgical drapes and materials in varying concentrations of oxygen Anesthesiology 119 (4) 770-776

Daane SP, Toth BA 2005 Fire in the Operating Room: Principles and Prevention Plastic and Reconstructive Surgery 115 (5) 73-75 
Darouiche RO, Wall MJ Jr, Itani KM et al 2010 Chlorhexidine-Alcohol versus PovidoneIodine for Surgical-Site Antisepsis The New England Journal of Medicine 362 (1) 18-26

Day AT, Rivera E, Farlow JL, Gourin CG, Nussenbaum B 2018 Surgical Fires in Otolaryngology: A Systematic and Narrative Review Otolaryngology-Head and Neck Surgery 158 (4) 598-616

Dennison DA 2011 Scoring patients for fire risk adds to safety Nursing 41 (2) 67-68

Dorozhkin D, Olasky J, Jones DB et al 2017 OR fire virtual training simulator: design and face validity Surgical Endoscopy 31 (9) 3527-3533

ECRI Institute 2009 New clinical guide to surgical fire prevention Health Devices 200938 (10) 317

Goldberg J 2006 Brief laboratory report: surgical drape flammability AANA Journal 74 (5) $352-354$

Gorphe P, Sarfati B, Janot F et al 2014 Airway fire during tracheostomy European Annals of Otorhinolaryngology, Head and Neck Diseases 131 (3) 197-199

Haith LR Jr, Santavasi W, Shapiro TK et al 2012 Burn center management of operating room fire injuries Journal of Burn Care \& Research 33 (5) 649-653

Hart SR, Yajnik A, Ashford J, Springer R, Harvey S 2011 Operating Room Fire Safety The 
Ochsner Journal 11 (1) 37-42

Jones EL, Overbey DM, Chapman BC et al 2017 Operating Room Fires and Surgical Skin Preparation Journal of the American College of Surgeons 225 (1) 160-165

Jones TS, Black IH, Robinson TN, Jones EL 2019 Operating Room Fires Anesthesiology 130 $492-501$

Kaye AD, Kolinsky D, Urman RD 2014 Management of a fire in the operating room Journal of Anesthesia 28 (2) 279-287

Kezze I, Zoremba N, Rossaint R, Rieg A, Coburn M, Schälte G 2018 Risks and prevention of surgical fires : A systematic review Der Anaesthesist 67 (6) 426-447

Lampotang S, Gravenstein N, Paulus DA, Gravenstein D 2005 Reducing the incidence of surgical fires: supplying nasal cannulae with sub-100\% O2 gas mixtures from anesthesia machines Anesthesia \& Analgesia 101 (5) 1407-1412

Macdonald AG 1994 A brief historical review of non-anaesthetic causes of fires and explosions in the operating room British Journal of Anaesthesia 73 (6) 847-856

Mathias JM 2006 Scoring fire risk for surgical patients OR Manager 22 (1) 19-20

Miles LF, Scheinkestel CD, Downey GO 2015 Environmental emergencies in theatre and critical care areas: power failure, fire, and explosion Continuing Education in Anaesthesia 
Critical Care \& Pain 15 (2) 78-83

National Institute for Health and Care Excellence 2019 Surgical site infections: prevention and treatment (update) [online] Available from:

https://www.nice.org.uk/guidance/indevelopment/gid-ng10094 [Accessed March 2019]

Overbey DM, Townsend NT, Chapman BC et al 2015 Surgical Energy-Based Device Injuries and Fatalities Reported to the Food and Drug Administration Journal of the American College of Surgeons 221 (1) 197-205

Parremore R 2018 Introduction of the Surgical Site Fire Risk Assessment at The Lister Hospital, part of HCA Healthcare UK Journal of Perioperative Practice. https://doi.org/10.1177/1750458918813080

Rocos B, Donaldson LJ 2012 Alcohol skin preparation causes surgical fires Annals of the Royal College of Surgeons of England 94 (2) 87-89

Roy S, Smith LP 2015 Surgical Fires in Laser Laryngeal Surgery: Are We Safe Enough? Otolaryngology-Head and Neck Surgery 152 (1) 67-72

Sibia US, Connors K, Dyckman S et al 2016 Potential Operating Room Fire Hazard of Bone Cement The American Journal of Orthopedics 45 (7) 512-514

Smith LP, Roy S 2008 Fire/burn risk with electrosurgical devices and endoscopy fiberoptic cables American Journal of Otolaryngology 29 (3) 171-176 
Smith LP, Roy S 2011 Operating room fires in otolaryngology: risk factors and prevention American Journal of Otolaryngology 32 (2) 109-114

Sosis MB 2006 Anesthesiologists must do a better job of preventing operating room fires Journal of Clinical Anesthesia 18 (2) 81-82

Tan Z, Thong SY 2015 Surgical fire caused by electrocautery in ambient air Proceedings of Singapore Healthcare 24 (3) 195-197

Tola DH, Jillson IA, Graling P 2018 Surgical Fire Safety: An Ambulatory Surgical Center Quality Improvement Project AORN Journal 107 (3) 335-344

Vedbhushan ST, Mulla MA, Haroonrasid, Chandrashekhar DM 2013 Surgical Incision by High Frequency Cautery Indian Journal of Surgery 75 (6) 440-443

Vogel L 2018 Surgical fires: nightmarish "never events" persist Canadian Medical Association Journal 190 (4) e120. https://doi.org/10.1503/cmaj.109-5548

Watson DS 2010 New Recommendations for Prevention of Surgical Fires AORN Journal 91 (4) $463-469$

Wolf GL, Sidebotham GW 1999 Endotracheal tube fire: comments on the advisability of not extubating Anesthesiology 91 (3) 888-889 
Yardley IE, Donaldson LJ 2010 Surgical fires, a clear and present danger The Surgeon 8 (2) $87-92$

Zahiri HR, Stromberg J, Skupsky H et al 2011 Prevention of 3 "never events" in the operating room: fires, gossypiboma, and wrong-site surgery Surgical Innovation 18 (1) 55-60 
